
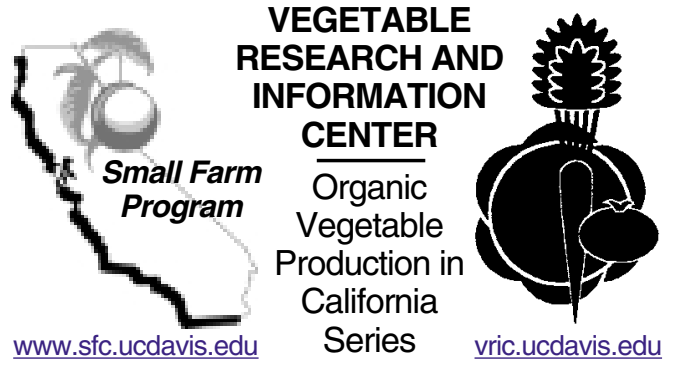

\section{POSTHARVEST HANDLING FOR ORGANIC CROPS}

\author{
TREVOR SUSLOW, \\ UC Cooperative Extension \\ Vegetable Crops Specialist, \\ UC Davis
}

Specific information on organic vegetable production practices in California is scarce, and growers need sound information
to guide their management decisions. The Organic Vegetable Production in California Series is made up of publications
written by Farm Advisors and Specialists from the University of California's Division of Agriculture and Natural
Resources. Each publication addresses a key aspect of organic production practices applicable to all vegetable crops.

Optimal-quality organic produce that achieves the desired textural properties, sensory shelf life, and nutritional content is the combined result of careful implementation of recommended production inputs and practices, careful handling at harvest, and appropriate postharvest handling and storage. This publication is an overview of general postharvest handling considerations unique to the marketing of registered or certified organic produce, with a brief introduction to currently permitted and restricted postharvest treatments.

\section{PLANNING FOR POSTHARVEST QUALITY}

The effort to achieve an economic reward through the marketing of organic produce must begin well before harvest. Seed selection can be a critical factor in determining the postharvest performance of any commodity. Individual cultivars vary in their inherent potential for firmness retention, uniformity, disease and pest resistance, and sensory shelf life, to list a few key traits. Cultivars chosen for novelty or heirloom traits may be suitable for small-scale production and local marketing but would be disastrous choices if the marketing plan included shipment to more distant markets. In addition to genetic traits, environmental factors such as soil type, temperature, wind during fruit set, frost, and rainy weather at harvest can have adverse effects on storage life, suitability for shipping, and quality. Cultural practices may have dramatic impacts on postharvest quality. For example, poor seedbed preparation for carrots may result in sunburned shoulders and green cores in many of the specialty carrots favored by consumers at farmer's markets. Other titles in the Organic Vegetable Production in California Series give more detail on suitable production practices.
Planning for postharvest food safety should be included in any crop management plan. Good Agricultural Practices (GAP) need to be developed and formalized for each crop and specific production field to minimize the risk of a variety of hazards or contaminants: chemical (e.g., heavy metals carryover), physical (e.g., sand and soil, wood, plastic or metal shards), and biological (e.g., Salmonella, Listeria, mycotoxins). Prior land use, adjacent land use, water source and method of application, fertilizer choice (such as the use of manure), compost management, equipment maintenance, field sanitation, movement of workers between different operations, personal hygiene, domestic animal and wildlife activities, and other factors have the potential to adversely impact food safety.

It is worth noting that many elements of a GAP plan are likely to be incorporated into the existing organic crop management program and activities. Programs in place to ensure produce quality may be directly applicable to food safety with minor modifications. The application of food safety programs, in turn, has been shown to directly benefit postharvest quality.

Once prerequisite production programs are in place, a systematic evaluation and implementation plan of Good Agricultural Practices during harvest operations and any subsequent postharvest handling, minimal or fresh-cut processing, and distribution to consumers must be developed. Considerations for these activities are covered below.

\section{HARVEST HANDLING}

The inherent quality of produce cannot be improved after harvest, only maintained for the expected window of time (shelf life) characteristic of the commodity. Part of what makes for successful postharvest handling is an 


\section{Postharvest Handling for Organic Crops • 2}

accurate knowledge of what this window of opportunity is under your specific conditions of production, season, method of handling, and distance to market. Under organic production, growers harvest and market their produce at or near peak ripeness more commonly than in many conventional systems. However, organic production often includes more specialty varieties whose shelf lives and shipping traits are reduced or even inherently poor. As a general approach, the following practices can help you maintain quality:

1. Harvest during the coolest time of day to maintain low product respiration.

2. Avoid unnecessary wounding, bruising, crushing, or damage from humans, equipment, or harvest containers.

3. Shade the harvested product in the field to keep it cool. By covering harvest bins or totes with a reflective pad, you greatly reduce heat gain from the sun, water loss, and premature senescence.

4. If possible, move the harvested product into a cold storage facility or postharvest cooling treatment as soon as possible. For some commodities, such as berries, tender greens, and leafy herbs, one hour in the sun is too long.

5. Do not compromise high quality product by mingling it with damaged, decayed, or decay-prone product in a bulk or packed unit.

6. Only use cleaned and, as necessary, sanitized packing or transport containers.

These operating principles are important in all operations but carry special importance for many organic producers who have less access to postharvest cooling facilities.

\section{POSTHARVEST STORAGE}

Temperature is the single most important tool for maintaining postharvest quality. For products that are not field-cured or exceptionally durable, the removal of field heat as rapidly as possible is highly desirable. Harvesting cuts a vegetable off from its source of water, but it is still alive and will lose water, and therefore turgor, through respiration. Field heat can accelerate the rate of respiration and with it the rate of quality loss. Proper cooling protects quality and extends both the sensory (taste) and nutritional shelf life of produce. The capacity to cool and store produce gives the grower greater market flexibility. Growers have a tendency to underestimate the refrigeration capacity needed for peak cooling demand. It is often critical that fresh produce rapidly reach the optimal pulp temperature for short-term storage or shipping if it is to maintain its highest visual quality, flavor, texture, and nutritional content. The five most common cooling methods are described below.

Room cooling - an insulated room or mobile container equipped with refrigeration units. Room cooling is slower than other methods. Depending on the commodity, packing unit, and stacking arrangement, the product may cool too slowly to prevent water loss, premature ripening, or decay.

Forced-air cooling - fans used in conjunction with a cooling room to pull cool air through packages of produce. Although the cooling rate depends on the air temperature and the rate of airflow, this method is usually 75 to $90 \%$ faster than simple room cooling. Design considerations for a variety of small- and large-scale units are available in Commercial Cooling of Fruit, Vegetables, and Flowers (ANR Publication 21567).

Hydrocooling - showering produce with chilled water to remove heat, and possibly to clean produce at the same time. The use of a disinfectant in the water is essential, and some of the currently permitted products are discussed later in this publication. Hydrocooling is not appropriate for all produce. Waterproof containers or water-resistant waxedcorrugated cartons are required. Currently waxed corrugated cartons have limited recycling or secondary use outlets, and reusable, collapsible plastic containers are gaining popularity. A list of vegetables that are suitable for hydrocooling is available in Postharvest Technology of Horticultural Crops (ANR Publication 3311) as well as in Commercial Cooling of Fruit, Vegetables, and Flowers.

Top or liquid icing - an effective method to cool tolerant commodities, and equally adaptable to small- or large-scale operations. Ice-tolerant vegetables are listed in Postharvest Technology of Horticultural Crops and in Commercial Cooling of Fruit, Vegetables, and Flowers. It is essential that you ensure that the ice is free of chemical, physical, and biological hazards.

Vacuum cooling - uses a vacuum chamber to cause the water within the plant to evaporate, removing heat from the tissues. This system works well for leafy crops that have a high surface-to-volume ratio, such as lettuce, spinach, and celery. The operator may spray water onto the produce before placing it into the vacuum chamber. As with hydrocooling, proper water disinfection is essential (see Sanitation and Water Disinfection). The high cost of the vacuum chamber system restricts its use to larger operations. 
The considerations for and selection of appropriate cooling methods and appropriate storage temperature and humidity conditions for a large diversity of vegetables are discussed in the two ANR publications mentioned above. In large cooling operations that handle both conventional and organic commodities, it is common to hydrocool (or water-spray vacuum-cool) organic produce at the beginning of daily operation, after a full cleaning of the facility and a complete water exchange. This practice is intended to prevent carryover or cross-contamination of organic produce with synthetic pesticide or other prohibited residues. This will generally require at least overnight short-term storage of the produce. The injection of ozone into the cooling water stream has been shown to reduce substantially the pesticide residues that may remain in the water after it is used to cool non-organic produce.

Other postharvest issues that involve combined steps of unloading commodities from harvest bins, washing, and precooling must also be evaluated for adherence to organic standards. Some operators use flotation as a way to reduce damage at the point of grading and packing. Entire bins are submerged in a tank of water treated with a chemical flotation aid that allows the picked product to be gently removed and separated from the container. Lignin sulfonates are allowed in certified organic handling as flotation aids for water-based unloading of field bins or other density separation applications.

\section{SANITATION AND WATER DISINFECTION}

Preventive food safety programs, sanitation of equipment and food contact surfaces, and water disinfection should be integrated into every facet of postharvest handling. Food safety and decay/spoilage control are concerns for produce handlers at all scales of production. Escherichia coli (E. coli) O157:H7, Salmonella, Shigella, Listeria, Cryptosporidium, Hepatitis, and Cyclospora are among the diseases and disease-causing organisms that have been associated with fresh fruits and vegetables. Several cases of foodborne illness have been traced to poor or unsanitary postharvest practices, especially to nonpotable cooling water and ice.

For organic handlers, the nature and prior use of cooling water is a special consideration. Postharvest water cannot at any time contain prohibited substances in dissolved form. Responsibility for this applies to the organic producer, handler, processor, and retailer. Even incidental contamination from a prohibited material would keep the product from being certified organic. Organic producers, packers, and handlers are required to keep accurate, specific records of postharvest wash or rinse treatments, identified by brand name and source.
For a more complete discussion of water disinfection, see Postharvest Chlorination (ANR Publication 8003).

Briefly, the proper use of a disinfectant in postharvest wash and cooling water can help prevent both postharvest diseases and foodborne illnesses. Because most municipal water supplies are chlorinated and the vital role of water disinfection is well recognized, organic growers, shippers, and processors may use chlorine within specified limits. All forms of chlorine (e.g., liquid sodium hypochlorite, granular calcium hypochlorite, and chlorine dioxide) are restricted materials as defined by existing organic standards. The application must conform with Maximum Residual Disinfectant Limit under the Safe Drinking Water Act, currently $4 \mathrm{mg} / \mathrm{L}$ (4 ppm) expressed as $\mathrm{Cl}_{2}$. The California Certified Organic Farmers (CCOF) regulations have permitted this threshold of $4 \mathrm{ppm}$ residual chlorine, measured downstream of the product wash (due to food safety concerns, CCOF has recently modified this threshold to permit $10 \mathrm{ppm}$ residual chlorine measured downstream of the wash step). Growers certified by other agencies should check with their certifying agent.

As a general practice, field soil on product, bins, totes, and pallets should be kept to a minimum by prewashing the produce before loading it. This will significantly reduce the demand for disinfectant in the water and lower the total required volume of antimicrobial agents. Prewashing also removes plant exudates released from harvest cuts or wounds, which can react rapidly with oxidizers such as hypochlorite and ozone, and so requires higher rates of the chemical to maintain the target 4 to $10 \mathrm{ppm}$ downstream activity.

For both organic and conventional operations, liquid sodium hypochlorite is the most common form used. For optimum antimicrobial activity with a minimal concentration of applied hypochlorite, the $\mathrm{pH}$ of the water must be adjusted to between 6.5 and 7.5. At this $\mathrm{pH}$ range, most of the chlorine is in the form of hypochlorous acid $(\mathrm{HOCl})$, which delivers the highest rate of microbial kill and minimizes the release of irritating and potentially hazardous chlorine gas $\left(\mathrm{Cl}_{2}\right)$. Chlorine gas will exceed safe levels if the water is too acidic. Products used for $\mathrm{pH}$ adjustment also must be from a natural source such as citric acid, sodium bicarbonate, or vinegar. Calcium hypochlorite, properly dissolved, may provide benefits of reduced sodium injury to sensitive crops (e.g., some apples varieties), and limited evidence points toward extended shelf life for tomatoes and bell peppers due to calcium uptake. Amounts of sodium hypochlorite to add to clear, clean water for disinfection are given in the table on the next page.

Ozone is an attractive option for water disinfection and other postharvest applications. Ozonation is a 
Table. Quantities and concentrations of sodium hypochlorite needed to disinfect water for produce cooling, with a downstream target concentration not to exceed 10 ppm $^{*}$

\begin{tabular}{lccc}
\hline Concentration & $\begin{array}{c}\text { Upstream } \\
\text { target ppm }\end{array}$ & Fl. oz./5 gal. & Cups/50 gal. \\
\hline Sodium hypochlorite (a.i. 5.25\%) & 25 & 0.28 & 0.25 \\
& 50 & 0.55 & 0.50 \\
Sodium hypochlorite (a.i.12.7\%) & 75 & 0.80 & 0.75 \\
& 100 & 1.10 & 1.00 \\
& 25 & 0.06 & 0.05 \\
& 50 & 0.12 & 0.10 \\
& 75 & 0.17 & 0.15 \\
\hline
\end{tabular}

* Organic certification standards permit a maximum of $10 \mathrm{ppm}$ residual chlorine downstream of the product wash step. The specific crop, water source and quality, water $\mathrm{pH}$, and other factors will influence the total upstream sodium hypochlorite needed to maintain this target level. A general starting point is $50 \mathrm{ppm}$ for produce with low soil content or minimal tissue damage and cell leakage (such as from harvest cuts) following harvest. Some products, such as spring mix, may require higher initial upstream chlorination because the high amounts of organic compounds released from harvest wound sites tie up available hypochlorous acid. This is best determined in practice and on site with appropriate monitoring equipment or kits, which include titration methods in combination with oxidation-reduction potential (ORP) probes. Background information and sources of monitoring kits and equipment are available from the UC Postharvest Technology Research and Information Center (http://postharvest.ucdavis.edu). Higher levels of sodium hypochlorite or other chlorinated products are permissible for equipment surface and crate or tote cleaning, provided that treatment is followed by a thorough clean-water rinse (see Cleaners, Sanitizers, and Disinfectants).

powerful oxidizing treatment and is effective against chlorine-resistant decay microbes and foodborne pathogens, acting far more quickly than permissible concentrations of chlorine. This may be a distinct advantage for cooling or wash procedures with short contact times. Ozone oxidative reactions create far fewer disinfection by-products (e.g., trihalomethanes are a health and environmental concern) than chlorination. You may decide to use ozonation rather than chlorination in your organic postharvest operation despite capital and operating costs that are higher than for chlorine or other available methods.

Ozone must be generated on-site at the time of use and has a very low stability, as short as 20 minutes even in clear water. Clear water is essential for optimal performance, and adequate filtration of input or recirculating water is needed. Depending on scale and ozone generation output, complete-system costs start at about $\$ 10,000$. Small-scale units are available for a few thousand dollars and are suitable for limited water use and small-batch applications. For specifications and installation, consult an experienced ozone service provider.

Food-grade hydrogen peroxide (0.5 to $1 \%$ ) and peroxyacetic acid are additional options. In general, peroxyacetic acid (PAA) has good efficacy in water dump tanks and water flume sanitation applications. PAA has very good performance, compared to chlorine and ozone, in removing and controlling microbial biofilms (tightly adhering slime) in dump tanks and flumes. At this time, one disadvantage is a higher cost per unit; another is that availability is restricted to large bulk units.

\section{CLEANERS, SANITIZERS, AND DISINFECTANTS}

A partial list of allowed cleaners, disinfectants, sanitizers, and postharvest aides follows.

Acetic acid - allowed as a cleanser or sanitizer. The vinegar used as an ingredient must be from an organic source.

Alcohol (ethyl) - allowed as a disinfectant. Alcohol must be from an organic source.

Alcohol (isopropyl) - may be used as a disinfectant under restricted conditions.

Ammonium sanitizers - quaternary ammonium salts are a general example in this category. Quaternary ammonium may be used on non-food-contact surfaces. Its use is prohibited on food contact surfaces, except for specific equipment where alternative sanitizers significantly increase equipment corrosion. Detergent cleaning and rinsing procedures must follow quaternary ammonium application. Monitoring 


\section{Postharvest Handling for Organic Crops • 5}

must show no detectable residue prior to the start of organic packaging (e.g., fresh-cut salads).

Bleach - calcium hypochlorite, sodium hypochlorite, and chlorine dioxide allowed as sanitizers for water and food contact surfaces. In California, product (fresh produce) wash water treated with chlorine compounds as a disinfectant cannot exceed $10 \mathrm{ppm}$ residual chlorine measured downstream of product contact.

Detergents - allowed as equipment cleaners. This category also includes surfactants and wetting agents. Products must be evaluated on a case-by-case basis.

Hydrogen peroxide - allowed as a water and surface disinfectant.

Ozone - considered GRAS (Generally Regarded As Safe) for produce and equipment disinfection. Exposure limits for worker safety apply.

Peroxyacetic acid - water disinfectant and fruit and vegetable surface disinfectant.

\section{OTHER POSTHARVEST TREATMENTS}

There are three additional postharvest treatments that may be used on produce:

Carbon dioxide - permitted for postharvest use in modified- and controlled-atmosphere storage and packaging. For crops that tolerate treatment with elevated $\mathrm{CO}_{2}(\geq 15 \%)$, suppression of decay and control of insect pests can be achieved.

Fumigants - allowed if materials are naturally occurring forms (e.g., heat-vaporized acetic acid). Materials must be from a natural source.

Wax - must not contain any prohibited synthetic substances. Acceptable sources include carnuba or wood-extracted wax. Products that are coated with approved wax must be so indicated on the shipping container.

\section{IMPORTANCE OF OPTIMAL STORAGE AND SHIPPING TEMPERATURES}

Although we stress rapid and adequate cooling as a primary method of postharvest handling, many vegetables are subtropical in origin and susceptible to chilling injury. Chilling injury occurs when sensitive crops are exposed to low temperatures that are above the freezing point. Damage often is induced by a very brief exposure, but may not become apparent for several days or until transfer to warmer display conditions. Some examples of sensitive crops are basil, tomato, eggplant, green beans, okra, and yellow crookneck squash. Different parts of some vegetables have distinct sensi- tivities. In eggplant, the cap or calyx is more sensitive and turns black before the fruit itself is affected. The effects of chilling injury are cumulative in some crops. Chilling injury may not be apparent until produce is removed from low-temperature storage. Depending on the duration and severity of chilling, chilling symptoms become evident in the following ways several hours or a few days after the produce is returned to warmer temperatures:

- pitting and localized water loss

- browning or other skin blemishes

- internal discoloration

- increased susceptibility to decay

- failure to ripen or uneven color development

- Loss of flavor, especially characteristic volatiles

- Development of off-flavors

Temperature management also plays a key role in limiting water loss in storage and transit. As the primary means of lowering respiration rates of fruits and vegetables, temperature has an important relationship to relative humidity and thus directly affects the product's rate of water loss. The relative humidity of the ambient air conditions in relation to the relative humidity of the crop (essentially 100\%) directly influences the rate of water loss from produce at any point in the marketing chain. Water loss may result in wilting, shriveling, softening, browning, stem separation, or other defects.

Transport to and display at roadside stands or farmer's markets often result in extended periods of exposure of sensitive produce to direct sun, warm (or even high) temperatures, and low relative humidity. Rapid water loss under these conditions can result in limp, flaccid greens and a loss of appealing natural sheen or gloss in fruits and vegetables. By providing postharvest cooling before and during transport and a shading structure during display, you can minimize rapid water loss at these market outlets.

Approved fruit and vegetable waxes are effective tools for reducing water loss and enhancing produce appearance. The uniform application and coverage for waxes or oils using proper packing line brushes or rolling sponges is important. Plastic wraps or other food-grade polymer films retard water loss. Adequate oxygen exchange is necessary to prevent fermentative respiration and the development of ethanol and offodors or flavors. Wraps or bags must have small perforations or slits to prevent these conditions, especially when temperature management is not available. The exposure of bagged or tightly wrapped produce to direct sunlight will cause the product's internal temperature to rise rapidly. Water loss will result and, as cool- 


\section{Postharvest Handling for Organic Crops • 6}

ing follows, free water will condense, possibly leading to accelerated decay.

Specialized films that create modified atmospheres (MA) when sealed as a bag or pouch are available for many produce items that have well-characterized tolerances for low oxygen and elevated carbon dioxide. Not all commodities benefit from MA.

Packing design and packaging can also be designed to minimize water loss. To minimize condensation inside the bag and reduce the risk of microbial growth, the bags may be vented, microperforated, or made of material permeable to water vapor. Barriers to water loss may also function as barriers to cooling, and packing systems should be carefully selected for the specific application with this in mind. Packaging materials, storage or transport containers, or bins that contain synthetic fungicides, preservatives, or fumigants (or any bag or container that has previously been in contact with any prohibited substance) are not allowed for organic postharvest handling. In small-scale handling, the reuse of corrugated containers from conventional produce is strongly discouraged by organic certifying organizations. Reuse of hard-to-clean containers that held conventional produce may even be prohibited by specific organic registration or certifying authorities.

During transportation and storage, relative humidity (more properly, vapor pressure deficit) is critical, even at a low temperature. For a more complete discussion of optimal relative humidity for fruits and vegetables and the principles for prevention of water loss see Commercial Cooling of Fruit, Vegetables, and Flowers (ANR Publication 21567).

\section{ETHYLENE}

The management of ethylene may be another postharvest consideration for quality maintenance during storage and transportation. Ethylene is a natural hormone produced by plants and is involved in many natural functions during development, including ripening. Ethylene treatments may be applied for degreening or to accelerate ripening events in fruits harvested at a mature but unripe developmental stage. For a detailed discussion of the role of ethylene in ripening and postharvest management, see Postharvest Technology of Horticultural Crops (ANR Publication 3311).

In organic handling, ethylene gas produced by catalytic generators is prohibited for all products except bananas. As the majority of ethylene-responsive organic produce is harvested nearly or fully ripe, this restriction does not currently constitute a significant barrier.

In contrast to its role in ripening, ethylene from plant sources or environmental sources (e.g., combustion of propane in lift trucks) can be very damaging to sensi- tive commodities. In brief, ethylene producers should not be stored with fruits or vegetables that are sensitive to it. External ethylene will stimulate loss of quality, reduce shelf life, increase disease, and induce specific symptoms of ethylene injury, such as the following:

- russet spotting of lettuce

- yellowing or loss of green color (for example, in cucumber, broccoli, kale, spinach)

- increased toughness in turnips and asparagus spears

- bitterness in carrots and parsnips

- yellowing and abscission (dropping) of leaves in Brassicas

- softening, pitting, and development of off-flavor in peppers, summer squash, and watermelons

- browning and discoloration in eggplant pulp and seed

- discoloration and off-flavor in sweet potatoes

- increased ripening and softening of mature green tomatoes

Besides providing adequate venting or fresh air exchange, you can use ethylene adsorption or conversion systems that are designed to prevent damaging levels (as low as $0.1 \mathrm{ppm}$ for some items) from accumulating in storage and during transportation. Potassium permanganate $\left(\mathrm{KMnO}_{4}\right)$ air filtration systems or adsorbers are allowed for postharvest handling, provided that strict separation from product contact is ensured. Other air filtration systems available for ethylene removal in cold rooms are based on glass-rods treated with a titanium dioxide catalyst and ultraviolet light inactivation. In addition, ultraviolet light-ozone-based systems of ethylene elimination are commercially available.

\section{SPECIAL ISSUES}

Although irradiation technologies are strongly disfavored by much of the organic food industry, X-ray irradiation is allowed for metal detection in packing. Metal detection is a common practice in many minimally processed and packaged organic vegetables and salad mixes.

The use of incompletely composted animal manure in organic production is prohibited due to postharvest food safety concerns. Organic standards specify a waiting period of from 60 to 120 days, depending on certifying agency and crop, between the date the composted animal manure is applied to the soil and the date a crop intended for human consumption is planted. The California Certified Organic Farmers organization $(\mathrm{CCOF})$ requires that all animal manure used for soil 


\section{Postharvest Handling for Organic Crops $\quad \begin{aligned} & \mathbf{7} \\ & \text { P }\end{aligned}$}

amendment be composted or treated according to current standards for Class A level pathogen reduction, as specified by the U.S. Environmental Protection Agency (EPA). Documentation of the compost process conditions for each batch is an essential part of the required record keeping that ensures compliance with preventive food safety programs. In addition, composting reduces the potential for inhibition of plant growth that is often associated with the use of raw manure. Properly composted manure can be applied directly to growing vegetable crops with little concern. However, although composting can degrade many if not most organic contaminants (i.e., pesticides), it cannot eliminate heavy metals. The composting process concentrates heavy metals that are a concern with sewage sludge (biosolids), a composted product occasionally used in production that can impact postharvest safety. Biosolids are prohibited from use by many organic certification organizations, including the CCOF.

Shippers must be aware of special requirements for transporting organic product whether by highway truck, air carrier, or containerized marine and intermodal shipping. Mixed-load shipment of organic and conventional product is permitted if "Organic" labeling is prominently and clearly displayed. In addition, there must be no risk that organic commodities will be contaminated by or come into direct contact with conventional product. Typically, carriers of bulk, raw organic product must maintain complete records of clean-out dates and products. Procedures for transport carrier cleaning or other treatments must include steps to prevent contamination from cleaners or fumigants, ripening agents, pest control agents, diesel fumes, and vehicle maintenance products.

\section{OTHER PUBLICATIONS IN THIS SERIES}

Organic Certification, Farm Production Planning, and Marketing,

UC ANR Publication 7247

Soil Management and Soil Quality for Organic Crops, UC ANR Publication 7248

Soil Fertility Management for Organic Crops, UC ANR Publication 7249

Weed Management for Organic Crops, UC ANR Publication 7250

Insect Pest Management for Organic Crops, UC ANR Publication 7251

Plant Disease Management for Organic Crops, UC ANR Publication 7252 


\section{RESOURCES}

\section{Postharvest Handling References}

Commercial Cooling of Fruits, Vegetables, and Flowers. 1998. J. F. Thompson, et. al., Oakland: University of California. ANR Publication 21567.

Commercial Storage of Fruits, Vegetables, and Florist and Nursery Stocks. 1986. USDA Agricultural Handbook \#66. R. E. Hardenburg, A. E. Watada, and C. Y. Wang.

Handling, Transportation, and Storage of Fruits and Vegetables. 1983. A. L. Ryall and W. J. Lipton. Westport, CT: AVI Publishing.

Marine Container Transport of Chilled Perishable Produce. 2000. J. F. Thompson, P. E. Brecht, T. Hinsch, and A. A. Kader. Oakland: University of California. ANR Publication 21595.

Postharvest Technology of Horticultural Crops. 1992. A. A. Kader, tech. ed. Oakland: University of California. ANR Publication 3311.

\author{
Other Resources \\ California Certified Organic Farmers, Certification \\ Handbook \\ http://wwww.ccof.org/section1.htm \\ Community Alliance with Family Farmers (CAFF), \\ Resource Directory \\ http://www.caff.org/sustain/resource groups.html \\ Organic Materials Review Institute \\ http://www.omri.org/ \\ UC Postharvest Technology Research and Information \\ Center \\ http://postharvest.ucdavis.edu \\ UC Small Farm Center \\ http://wwww.sfc.ucdavis.edu
}

An electronic version of this publication is available on the University of California ANR Communication Services Website at http:/ / anrcatalog.ucdavis.edu.

Publication 7254

(C) 2000 by the Regents of the University of California, Division of Agriculture and Natural Resources. All rights reserved.

To simplify information, trade names of products have been used. No endorsement of named products is intended, nor is criticism implied of similar products that are not mentioned.

\footnotetext{
The University of California prohibits discrimination against or harassment of any person employed by or seeking employment with the University on the basis of race, color, national origin, religion, sex, physical or mental disability, medical condition (cancer-related or genetic characteristics), ancestry, marital status, age, sexual orientation, citizenship, or status as a covered veteran (special disabled veteran, Vietnam-era veteran or any other veteran who served on active duty during a war or in a campaign or expedition for which a campaign badge has been authorized).

University Policy is intended to be consistent with the provisions of applicable State and Federal laws.

Inquiries regarding the University's nondiscrimination policies may be directed to the Affirmative Action/Staff Personnel Services Director, University of California, Agriculture and Natural Resources, 1111 Franklin, 6th Floor, Oakland, CA 94607-5200 (510) 987-0096.
} 